Correction

\title{
Correction: Duso C.; et al. Colonization Patterns, Phenology and Seasonal Abundance of the Nearctic Leafhopper Erasmoneura vulnerata (Fitch), a New Pest in European Vineyards. Insects 2020, 11, 731
}

\author{
Carlo Duso*(D), Giulia Zanettin, Pamela Gherardo, Giulia Pasqualotto (D, Damiano Raniero, Filippo Rossetto, \\ Paola Tirello and Alberto Pozzebon
}

check for

updates

Citation: Duso, C.; Zanettin, G.;

Gherardo, P.; Pasqualotto, G.; Raniero, D.; Rossetto, F.; Tirello, P.; Pozzebon,

A. Correction: Duso C.; et al.

Colonization Patterns, Phenology and Seasonal Abundance of the Nearctic Leafhopper Erasmoneura vulnerata (Fitch), a New Pest in European Vineyards. Insects 2020, 11, 731. Insects 2021, 12, 59. https://doi.org/ $10.3390 /$ insects 12010059

Received: 28 December 2020 Accepted: 4 January 2021 Published: 12 January 2021

Publisher's Note: MDPI stays neutral with regard to jurisdictional clai$\mathrm{ms}$ in published maps and institutional affiliations.

Copyright: (C) 2021 by the authors. Licensee MDPI, Basel, Switzerland. This article is an open access article distributed under the terms and conditions of the Creative Commons Attribution (CC BY) license (https:// creativecommons.org/licenses/by/ $4.0 /)$.
Department of Agronomy, Food, Natural Resources, Animals and Environment, University of Padova, Viale dell’Università 16, Agripolis, 35020 Legnaro, Padova, Italy; giuliazanettin22@gmail.com (G.Z.); pamela.gherardo@studenti.unipd.it (P.G.); giulia.pasqualotto.2@studenti.unipd.it (G.P.); damiano.raniero@studenti.unipd.it (D.R.); filippo.rossetto.1@studenti.unipd.it (F.R.); paola.tirello@unipd.it (P.T.); alberto.pozzebon@unipd.it (A.P.)

* Correspondence: carlo.duso@unipd.it; Tel.: +39-049-8272805

It has recently come to our attention that there were some mistakes in legends and figures reported in our study [1]. In Figures 5-10, "Istar" was reported instead of "Instar". Moreover, the legend of Figure 9 was corrected as follows: "The phenology of E. vulnerata in LO1 vineyard in the growing season of 2019. Arrows indicate pyrethrins treatments." and the legend of Figure 10 was corrected as follows: "The phenology of E. vulnerata in MO vineyard in the growing season of 2019". The corrected figures and legends are reported below.

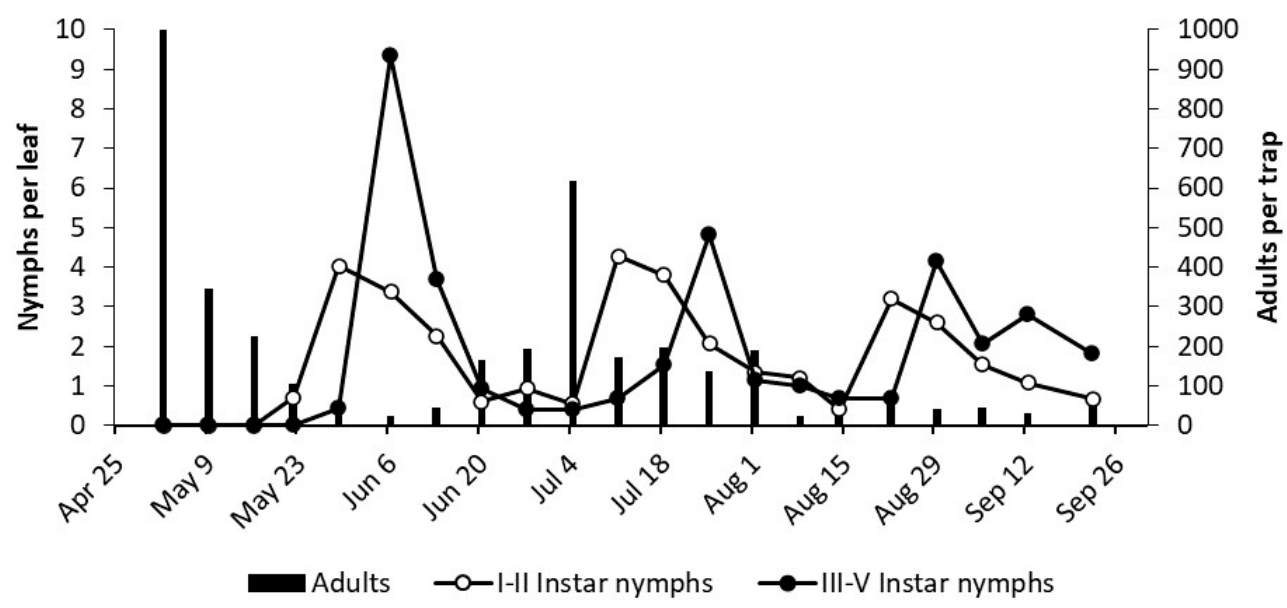

Figure 5. The phenology of E. vulnerata in AC vineyard in the growing season of 2017. 


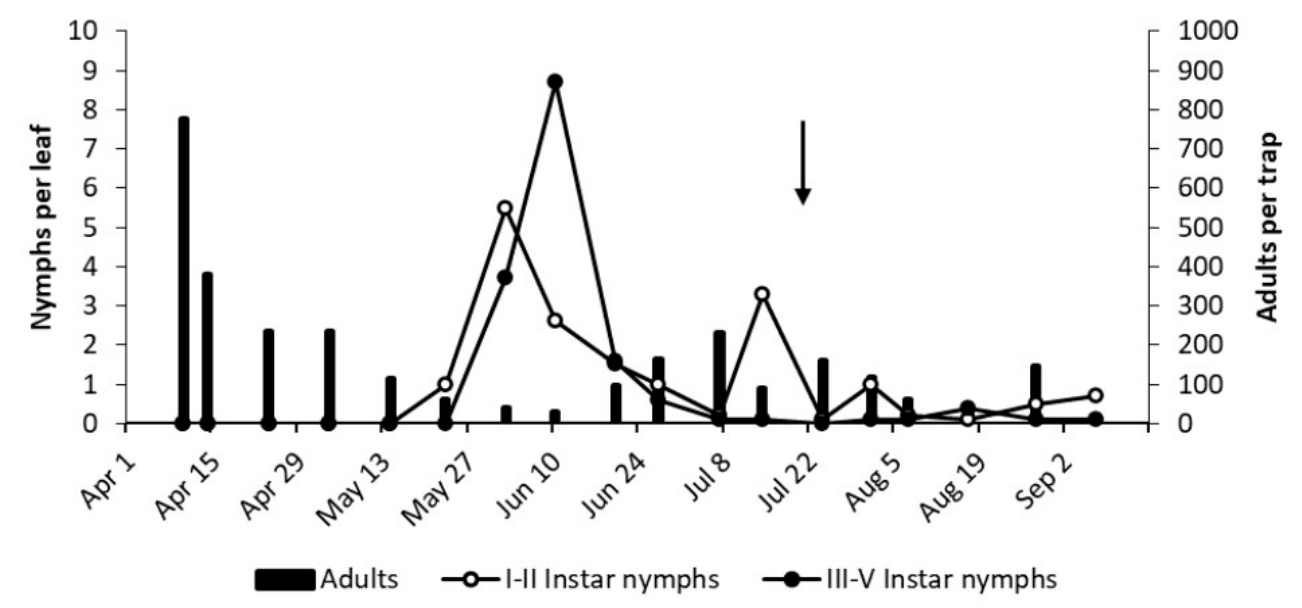

Figure 6. The phenology of E. vulnerata in AO vineyard in the growing season of 2017. Arrow indicates pyrethrins treatment.

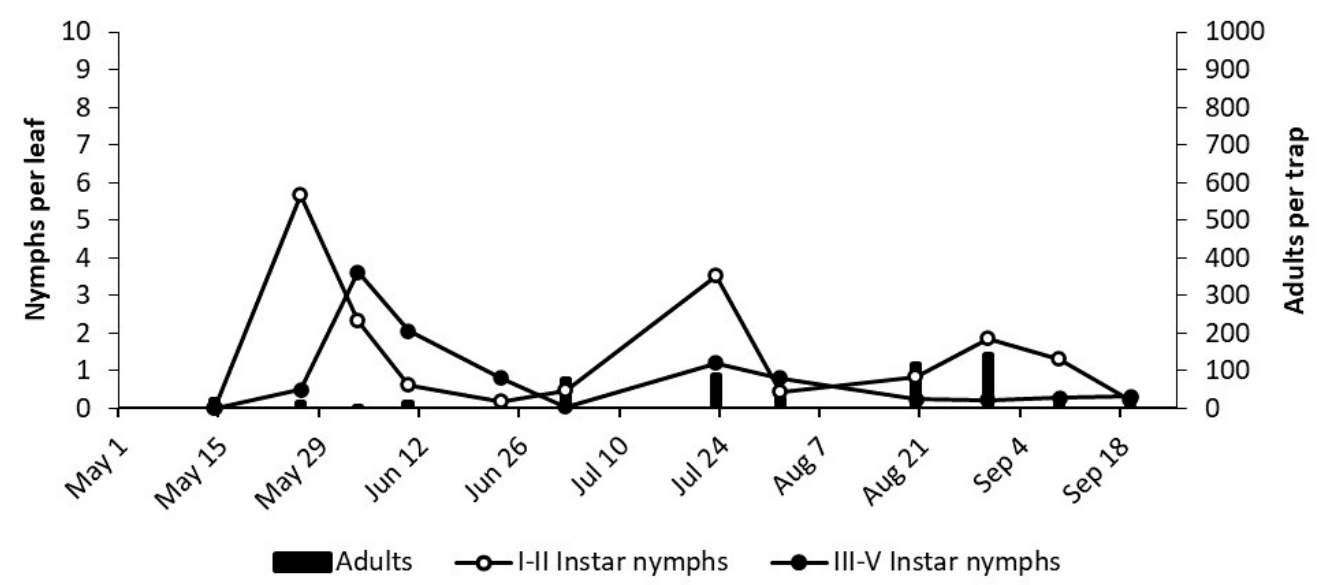

Figure 7. The phenology of E. vulnerata in MO vineyard in the growing season of 2018.

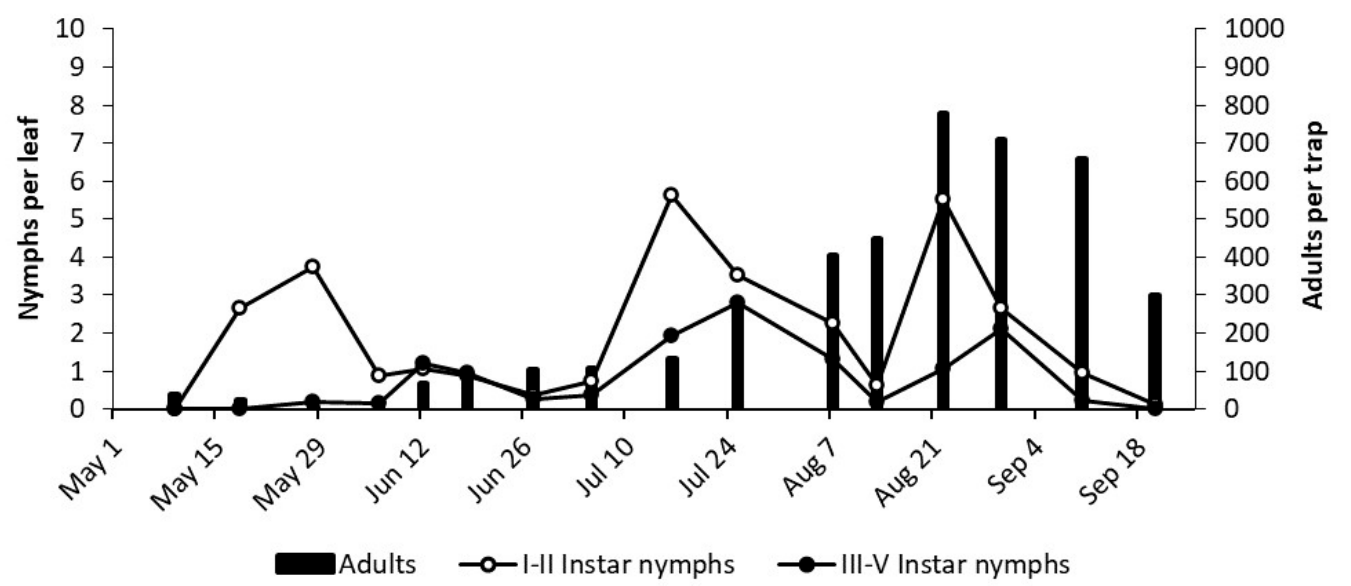

Figure 8. The phenology of E. vulnerata in LO2 vineyard in the growing season of 2018. 


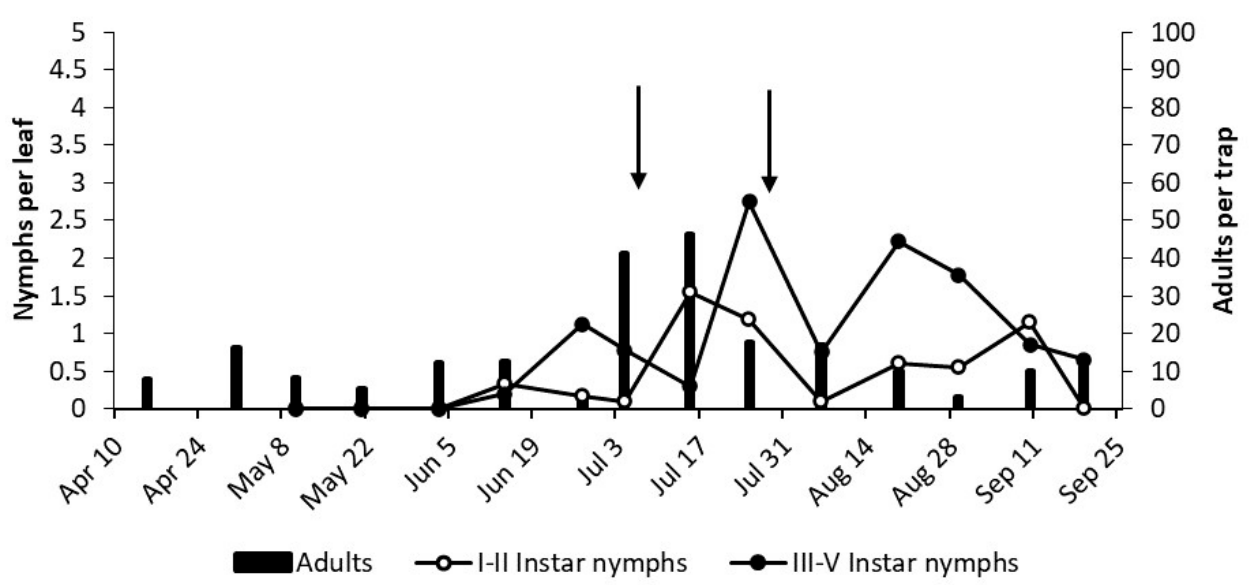

Figure 9. The phenology of E. vulnerata in LO1 vineyard in the growing season of 2019. Arrows indicate pyrethrins treatments.

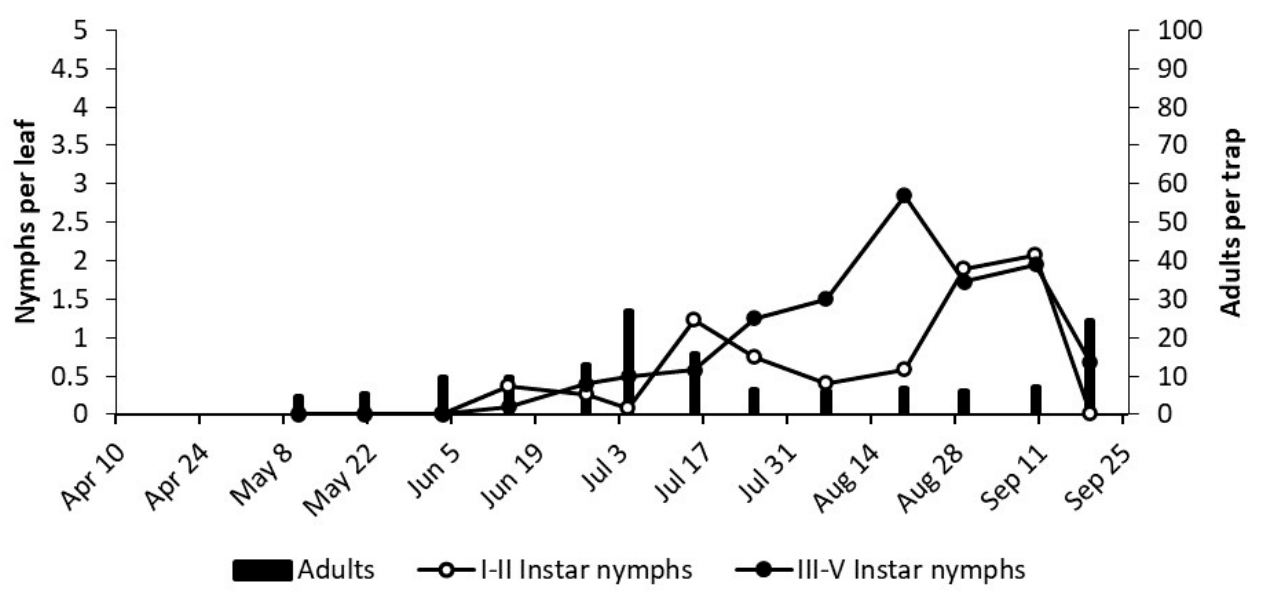

Figure 10. The phenology of E. vulnerata in MO vineyard in the growing season of 2019.

In the text, on page 10, Section 3.2.3, “2019”, Figures 9 and 10 should be cited instead of Figures 8 and 9.

The authors apologize for any inconvenience caused and state that the scientific conclusions are unaffected. The original article has been updated.

\section{Reference}

1. Duso, C.; Zanettin, G.; Gherardo, P.; Pasqualotto, G.; Raniero, D.; Rossetto, F.; Tirello, P.; Pozzebon, A. Colonization Patterns, Phenology and Seasonal Abundance of the Nearctic Leafhopper Erasmoneura vulnerata (Fitch), a New Pest in European Vineyards. Insects 2020, 11, 731. [CrossRef] [PubMed] 